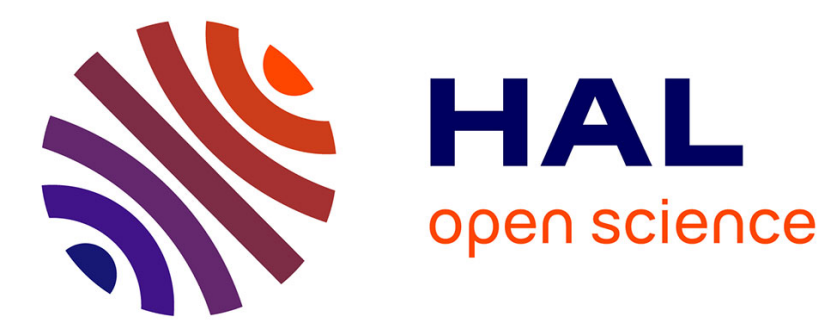

\title{
Minor Bleeds Alert for Subsequent Major Bleeding in Patients Using Vitamin K Antagonists.
}

Nic J.G.M. Veeger, Margriet Piersma-Wichers, Karina Meijer, Hans L. Hillege

\section{To cite this version:}

Nic J.G.M. Veeger, Margriet Piersma-Wichers, Karina Meijer, Hans L. Hillege. Minor Bleeds Alert for Subsequent Major Bleeding in Patients Using Vitamin K Antagonists.. British Journal of Haematology, 2011, 153 (4), pp.508. 10.1111/j.1365-2141.2011.08656.x . hal-00625169

\section{HAL Id: hal-00625169 https://hal.science/hal-00625169}

Submitted on 21 Sep 2011

HAL is a multi-disciplinary open access archive for the deposit and dissemination of scientific research documents, whether they are published or not. The documents may come from teaching and research institutions in France or abroad, or from public or private research centers.
L'archive ouverte pluridisciplinaire HAL, est destinée au dépôt et à la diffusion de documents scientifiques de niveau recherche, publiés ou non, émanant des établissements d'enseignement et de recherche français ou étrangers, des laboratoires publics ou privés. 


\section{b] british journal of haematology}

\section{Minor Bleeds Alert for Subsequent Major Bleeding in Patients Using Vitamin K Antagonists.}

\begin{tabular}{|c|c|}
\hline Journal: & British Journal of Haematology \\
\hline Manuscript ID: & BJH-2010-01799.R1 \\
\hline Manuscript Type: & Ordinary Papers \\
\hline $\begin{array}{r}\text { Date Submitted by the } \\
\text { Author: }\end{array}$ & 17-Feb-2011 \\
\hline Complete List of Authors: & $\begin{array}{l}\text { Veeger, Nic J.G.M.; University Medical Centre Groningen, } \\
\text { Epidemiology } \\
\text { Piersma-Wichers, Margriet; Thrombosis Service Groningen, --- } \\
\text { Meijer, Karina; University Medical Centre Groningen, Haematology } \\
\text { Hillege, Hans L.; University Medical Centre Groningen, } \\
\text { Epidemiology }\end{array}$ \\
\hline Key Words: & $\begin{array}{l}\text { Vitamin } \mathrm{K} \text { antagonists, Minor Haemorrhage, Major Haemorrhage, } \\
\text { Prevention, ANTICOAGULANTS }\end{array}$ \\
\hline
\end{tabular}

\section{SCHOLARONE"




\section{Minor Bleeds Alert for Subsequent Major Bleeding in Patients Using Vitamin K Antagonists.}

Running short title: Minor Bleeds Alert for Major Bleeding

Authors: Nic J.G.M. Veeger, PhD ${ }^{1,2}$; Margriet Piersma-Wichers, MD ${ }^{1,3}$ Karina Meijer, MD, $\mathrm{PhD}{ }^{1}$; Hans L. Hillege, MD, PhD ${ }^{2}$.

Department of Haematology, Division of Haemostasis and Thrombosis (1), Trial Coordination Centre, Department of Epidemiology (2), University Medical Centre Groningen - University of Groningen, Thrombosis Service Groningen (3), The Netherlands.

word count: 3304 summary: 200

Corresponding author

N.J.G.M. Veeger

Trial Coordination Centre, Department of Epidemiology, University Medical Centre Groningen

P.O.Box 30 001, 9700 RB, Groningen

Tel. +3150361 8064 (8061); Fax +31503618062

E-mail address: N.Veeger@tcc.umcg.nl

We would like to acknowledge prof.dr. Jan van der Meer who died last year. His contribution to our study was of utmost importance.

Financial disclosure: None of the authors had an affiliation with or financial involvement with any organisation or entity with a financial interest in or financial conflict with the subject matter or materials discussed in the manuscript. 


\section{SUMMARY}

Vitamin $\mathrm{K}$ antagonists (VKA) have shown to be effective in primary and secondary prevention of thromboembolism, but the associated risk of bleeding is an important limitation. The majority of the bleeds are clinically mild. In this study, we assessed whether these minor bleeds are associated with major bleeding, when controlling for other important risk indicators, including the achieved quality of anticoagulation. For this, 5898 patients of a specialised anticoagulation clinic were retrospectively studied for one year after initiation of VKA therapy. The risk of major bleeding was estimated using a multivariable piecewise exponential model with time-varying exposure for occurring minor bleeds.

In patients with a minor bleed ( $\mathrm{N}=1015)$ subsequent major bleeding occurred more frequently than in patients without a minor bleed $(\mathrm{N}=4883)$, with an incidence rate of $2.3(95 \% \mathrm{Cl} 1.4-$ 3.7) versus 1.2 per 100 person-years $(95 \% \mathrm{Cl} 0.9-1.7)$. The adjusted relative risk of subsequent major bleeding after a minor bleed was $2.9(95 \% \mathrm{Cl} 1.1-7.2, \mathrm{P}=0.024)$. The percentage of time above INR 5 was also independently associated with major bleeding, with a 2.2-fold increased risk in patients with at least $9 \%$ of time above INR 5 (95\% CI 1.3-4.0, $\mathrm{P}=0.006)$.

Minor bleeds alert for subsequent major bleeding, independent of the quality of anticoagulation.

Keywords: Anticoagulants; Vitamin K antagonists; Prevention; Minor Haemorrhage; Major Haemorrhage. 


\section{INTRODUCTION}

Vitamin $\mathrm{K}$ antagonists (VKA) are widely used in primary and secondary prevention of thromboembolism. Although these drugs have shown to be effective, the associated risk of bleeding is an important limitation (Schulman et al, 2008). Both effectiveness and risk of bleeding are related to the actual level of anticoagulation, expressed by the international normalized ratio (INR) (Schulman et al, 2008; Veeger et al, 2005). The intensity of anticoagulation widely varies within and between patients, due to environmental and genetic factors (Wilkinson, 2005; Ansell et al, 2008; Kucher et al, 2004; Wittkowsky \& Devine, 2004; Wittkowsky, 2005; Palareti et al, 2005; Penning-van Beest et al, 2001), as well as patients' compliance (van der Meer et al, 1997; McCormick et al, 2001). In this respect, the individual time spend below, within and above the INR target range can be used to identify patients on VKA who are at high risk of (recurrent) thromboembolism and bleeding (Veeger et al, 2005; Veeger et al, 2006).

Due to the above mentioned variability, a continued monitoring of the level of anticoagulation is mandatory. In the Netherlands, a unique nationwide network of 61 specialized anticoagulation clinics is responsible for the VKA management of all outpatients. In these specialized clinics, experienced physicians and dosing assistants are involved in optimizing VKA therapy, using computerized dosing programs and protocols for dose adjustments in case of under- and over-anticoagulation.

In assessing the risk of bleeding while using VKA, the primary focus is on major bleeding (Schulman et al, 2008). An important risk factor for major bleeding is the achieved level of anticoagulation. A previous major bleeding is also identified as a risk factor for subsequent major bleeding, although not consistently in all studies (The Stroke Prevention in Atrial Fibrillation Investigators, 1996; Beyth et al, 1998; Kuijer et al, 1999; White et al, 1996; Shireman et al, 2006). For a minor bleeding such an association has not yet been demonstrated. Minor bleeding might be due to over-anticoagulation or a pre-existing mild 
bleeding disorder, which is enhanced by VKA. In either case, the occurrence of a minor bleed during VKA therapy could alert for a high risk situation necessitating a renewed riskbenefit assessment of the VKA therapy in those patients.

In this study, we hypothesized that after a minor bleed, patients are at increased risk for subsequent major bleeding.

\section{METHODS}

\section{Patients and study design}

Patients originated from an inception cohort of 6758 consecutive patients referred to a large Dutch community based anticoagulation clinic for management of their VKA therapy from January $1^{\text {st }}, 1995$ to February $1^{\text {st }}, 1998$. During this period, data on level of anticoagulation, as well as bleeding complications was prospectively collected during the course of the VKA therapy by the anticoagulation clinic during the regular visits. The cohort is described in greater detail previously (Veeger et al, 2005; Veeger et al, 2006).

To assess the effect of the minor bleeds on the occurrence of subsequent major bleeding, we used the data of all patients collected over a period of 12 months after their first INR measurement by the anticoagulation clinic, or until the end of their treatment in case of a treatment duration of less than 12 months. To be able to fully address the possible association between minor and subsequent major bleeding in a time-dependent setting the minimum treatment duration was set to one month. Of the 6758 consecutive patients, 860 patients were excluded due to a late entry in the original cohort resulting in a treatment duration of less than one month $(\mathrm{N}=228)$, a discontinuation of VKA therapy within the first month ( $\mathrm{N}=549)$, an early major bleeding ( $\mathrm{N}=22 ; 6$ fatal) or death due to a non-bleeding cause within the first month $(\mathrm{N}=61)$. Thereby, our study population consisted of 5898 patients treated with VKA for at least one month $(\mathrm{N}=1361$, deep vein thrombosis; $\mathrm{N}=603$, pulmonary 
embolism; $\mathrm{N}=2328$, atrial fibrillation; $\mathrm{N}=842$, myocardial infarction; $\mathrm{N}=764$, prosthetic heart valve).

\section{Data collection}

\section{Patients' characteristics}

Patients' characteristics were collected from the records on file at the anticoagulation clinic. Baseline data included age, sex, co-morbidity, concomitant drugs and indication for VKA therapy.

\section{Anticoagulation data}

INR target range, as recommended by the Dutch Federation of Anticoagulation Clinics, was 2.5 to 3.5 in patients with venous thromboembolism or atrial fibrillation, and 3.0 to 4.0 in patients with myocardial infarction. In patients with a prosthetic heart valve, up to January 1 st 1997 the target range was INR 3.5 to 4.8 . From January 1 st 1997 onwards, it was lowered to INR 3.0 to 4.0 . In all patients, VKA dosing was performed using a nomogram based automated system, with control by experienced physicians. INR was measured once every 3 to 4 weeks or more frequently when appropriate, by the central laboratory of the anticoagulation clinic. In the initial phase, INR was checked more frequently, i.e. every 3 to 5 days. The dose was increased with predefined dose steps at INR values below the target range, and tapered at INR values exceeding the target range but less than 6.4. Treatment was interrupted for one day at INR values above 6.4 and vitamin $\mathrm{K}$ was additionally given in case of INR $>10.0$. The next measurement of INR was then performed within 3 days. The VKA of first choice was acenocoumarol. All data regarding anticoagulant therapy was stored in a computerized registration system. INR values, dates of measurements and dosage schedules were extracted from this system.

\section{Adverse events}


The physicians of the anticoagulation clinic registered all major bleeds, as a mandatory part of their quality system. Within the unique setting of VKA management in the Netherlands, patient education and awareness regarding the risks of VKA therapy also included reporting the occurrence of minor bleeds to the treating physicians. These bleeds were recorded. If treatment was interrupted due to a minor bleed, this was included. For this study, all information about major and minor bleeds, hospital admissions, treatment interruptions or cessation, and death during the treatment period was collected by the anticoagulation clinic. To minimize misclassification, all bleeding reports were adjudicated by an experienced haematologist who was not informed about the level of anticoagulation, nor about the occurrence of previous events, to assure a blinded classification.

\section{Clinical outcome}

Endpoints of clinical outcome were major and minor bleeds. Major bleeding was defined as a clinically overt bleed leading to transfusion, hospitalization and/or death, or a retroperitoneal, intracranial or intra-ocular bleed (Schulman \& Kearon, 2005). All reported overt bleeds that did not fulfil the criteria for major bleeding were classified as minor and included in the analysis as such. When a minor bleed required any medical intervention, it was classified as clinically relevant minor bleed.

\section{Statistical analysis}

Based on actual INR values, the day-to-day INR values were calculated by linear estimation, as proposed by Rosendaal et al with an adjustment of estimated values towards the next actual INR value (Veeger et al, 2005; Rosendaal et al, 1993). Linear estimation was not performed when time between to two assessments was more than 8 weeks, since the assumption of linearity was no longer judged as valid (Azar et al, 1996). From these day-today INR values, the amount of over-anticoagulation was estimated. For this, the percentage of time above INR 5.0 was calculated for each individual patient. A cut-off value of INR 5.0 
was chosen as above this level, the increase in the risk of major bleeding is clearly demonstrated (Veeger et al, 2005).

Those patients with the highest percentages of time above INR 5.0 were classified as "overanticoagulated". For this the upper quartile was a-priori defined. In these calculations, INR data after a major bleed was not included.

Absolute risks (incidence rates per 100 person years) of minor and major bleeding were assessed. Ninety-five percent confidence intervals $(95 \% \mathrm{Cl})$ around the incidence rates were calculated under the Poisson distribution assumption. In these calculations, the postevent follow-up time was not included.

The effect of over-anticoagulation (highest quartile of percentage time above INR 5.0) and minor bleeding on the risk of major bleeding was assessed using a piecewise exponential survival analysis approach. In this, the time at risk was divided into 11 one-month periods. As part of the piecewise exponential survival analysis, the acceptance of the exponential model, i.e. a constant hazard of major bleeding over the total study interval, was addressed (Allison, 1995).

Over-anticoagulation was assessed for each period. Minor bleeding was also incorporated in this analysis as a monthly-varying variable, in which the exposure status of the previous month was used to assess the associated risk of major bleeding.

In the multivariable analyses, sex, age, co-morbidity, concomitant drugs and indication for VKA therapy were included as potential confounders.

Reported P-values are two-sided and a P-value $<0.05$ was considered statistically significant. For all analyses, commercially available computer software (Statistical Analysis System version 9.2, SAS Institute, Cary, NC) was used. 


\section{RESULTS}

In total, 5898 consecutive patients were included in our study. Their characteristics and anticoagulation data are summarized in Table 1. Cumulative treatment time was 3892 patients-years, during which 117854 INR measurements were performed. Acenocoumarol was the predominantly used VKA (97\%). The remaining patients used phenprocoumon (2\%) or switched VKA during their treatment period (1\%). VKA was combined with low dose aspirin in $3 \%$ of patients. Median treatment time was 9.1 months (90\% central range, 1.4-11.8), during which 20 INR measurements were performed (median, $90 \%$ central range, $7-35)$. Based on all the actual measurements, median INR was 3.0 (90\% central range, 1.6-5.7). At a patient level, the median percentage of time spend above INR 5.0 was $3 \%(90 \%$ central range $0-23)$. When considering the patients that were classified as "over-anticoagulated" (i.e. a-priori defined as the upper quartile of patients with a highest amount of time above INR 5.0), these patients were at least $9 \%$ of their treatment time above INR 5.0 (median percentage of time above INR $5.0=15 \%$ (90\% central range 9-36).

\section{Clinical outcome}

\section{Minor bleeding}

A total of 1501 minor bleeds occurred in 1015 of 5898 patients (17\%), 716 patients had a single minor bleed (71\%), 194 patients two minor bleeds (19\%), and 105 patients multiple recurrent minor bleeds (10\%). The median INR at the time of the minor bleed was 3.3 (90\% central range 1.9-6.5). The absolute risk, expressed as the incidence rate per 100 personyears was $29.6(95 \% \mathrm{Cl}, 27.8-31.4)$. Haematomas (40\%), nose bleeds (27\%), conjunctiva bleeds (11\%) and haematuria (10\%) were the most frequently observed minor bleeds (Table 2). There was a difference in the occurrence of minor bleeds between women and men, mainly due to a difference in the number of haematomas and nose bleeds, with 418 and 241 in women vs. 177 and 167 in men. This resulted in a higher observed risk of minor bleeding 
in women than men (incidence rates $37.1,95 \% \mathrm{Cl}, 34.1-40.2$ in women vs. $23.1,95 \% \mathrm{Cl}$, 21.0-25.4 in men; rate ratio $1.6,95 \% \mathrm{Cl} 1.4-1.8, \mathrm{P}<0.001)$

A medical intervention, including temporary interruption, was required for 73 minor bleeds in 64 patients. These minor bleeds were classified as clinically relevant.

\author{
Major bleeding \\ Major bleeding occurred in 56 patients (0.9\%), with an incidence rate of 1.4 per 100 person- \\ years $(95 \% \mathrm{Cl}, 1.1-1.9)$. Nine major bleeds were fatal. The type of major bleeding is \\ presented in Table 3. The level of anticoagulation at the time of major bleeding, expressed \\ as the median INR was 3.4 (90\% central range $1.9-9.6)$.
}

\title{
Prediction of major bleeding
}

A higher risk of major bleeding was observed in the patients with a minor bleed. The incidence rate in these patients was 2.3 per 100 person-years $(95 \% \mathrm{Cl}, 1.4-3.7)$, whereas in patients without a prior minor bleed the incidence rate was 1.2 per 100 person-years (95\% $\mathrm{Cl}, 0.9-1.7)$. The incidence rate of major bleeding after a minor bleed was 3.9 per 100 person-years $(95 \% \mathrm{Cl}, 2.3-6.2)$. In this, follow-up time was restricted to the post-minor bleed period. Notably, in the 64 patients in whom a clinically relevant bleed had occurred, for which they received a medical intervention, including temporary interruption, major bleeding did not occur.

In addition, we performed a sensitivity analysis on the risk of major bleeding after a minor bleed, excluding the haematomas. This is especially relevant as to some degree misclassification of minor bleeds might have occurred. When excluding haematomas, in patients with a minor bleed the incidence rate of major bleeding was 2.6 per 100 personyears $(95 \% \mathrm{Cl}, 1.4-4.6)$. In the patients with a haematoma this was $1.9(95 \% \mathrm{Cl}, 0.7-4.2)$, not statistically significantly different (rate ratio $1.4(95 \% \mathrm{Cl}, 0.5-4.0, \mathrm{P}=0.53)$. When taking only 
the time after the minor bleed into consideration, incidence rates were $4.3(95 \% \mathrm{Cl}, 2.2-7.5)$ and $3.3(95 \% \mathrm{Cl}, 1.2-7.2)$, respectively (rate ratio $1.3 ; 95 \% \mathrm{Cl}, 0.5-3.7, \mathrm{P}=0.63)$.

Furthermore, also in the "over-anticoagulated" patients (highest quartile, more than $9 \%$ of treatment time above INR 5.0 ), major bleeding was more frequently observed. The incidence rate in these patients was 1.9 per 100 person-years $(95 \% \mathrm{CI}, 1.2-3.0)$, whereas in the patients in the lower three quartiles this was $1.2(95 \% \mathrm{Cl}, 0.9-1.7)$.

The adjusted relative risks associated with minor bleeding and over-anticoagulation were estimated using a multivariable piecewise exponential model. Both over-anticoagulation and prior minor bleeding were considered as time-dependent risk indicators, in which exposure as assessed for each 30-day period.

As shown in Figure 1, a minor bleed was an independent risk indicator with a 2.9-fold increased risk of major bleeding during the following month $(\mathrm{HR}=2.9,95 \% \mathrm{Cl}, 1.1-7.2, \mathrm{P}=$ 0.024). "Over-anticoagulation" was associated with a 2.2-fold increased risk of major bleeding $(\mathrm{HR}=2.2,95 \% \mathrm{Cl}, 1.3-4.0, \mathrm{P}=0.006)$. Additional independent risk indicators identified by multivariable analysis were diabetes mellitus, malignancy, use of diuretics (timedependent) and age above 70 years. Model evaluation resulted in acceptance of the exponential model (Lagrange multiplier test; $\mathrm{P}=0.12$ ), indicating that the hazard of major bleeding was constant over the one-year interval.

After excluding the haematomas, piecewise exponential survival analysis resulted in a crude hazard ratio for the risk of major bleeding after a minor bleed of $4.1(95 \% \mathrm{Cl}, 1.5-11.4$, $\mathrm{P}=0.007)$. After adjustment this reduced to $3.8(95 \% \mathrm{Cl}, 1.4-10.6, \mathrm{P}=0.010)$.

An additional analysis was performed using an exposure duration of two months. The crude hazard ratio for prior minor bleeding over the two-month period was $3.5(95 \% \mathrm{Cl} 1.7-$ $7.7, \mathrm{P}=0.001)$. The adjusted hazard ratio was $3.3(95 \% \mathrm{Cl} 1.5-7.0, \mathrm{P}=0.002)$, indicating that the increased risk lasts over the one-month period. 


\section{DISCUSSION}

To our knowledge, this study is the first to specifically address minor bleeding as potential risk indicator for major bleeding. We showed that the occurrence of a minor bleeding was associated with a 2.9-fold increased risk of major bleeding in the following month. This increased risk was independent of the amount of over-anticoagulation.

The absolute risk of major bleeding in our study was 1.4 per 100 person-years. Taking into consideration that our cohort consisted of unselected patients in whom VKA therapy was managed for one year by a specialized anticoagulation clinic, this absolute risk is in line with the rates reported previously (Schulman et al, 2008; Ansell et al, 2008; van der Meer et al, 1993; Palareti et al, 1996; van Es et al, 2002; Linkins et al, 2003; Palareti \& Cosmi, 2009). Our rate of minor bleeding of 29.6 per 100 person-years is more difficult to compare. In a recent large clinical trial in AF patients the rate of minor bleeding was 18.2 (Connolly et al, 2009). Two other large trials reported higher incidence rates for combined major and minor bleeding, ranging from 30 to 47 per 100 person-years (Albers et al, 2005; Olsson, 2003).

Our finding regarding the quality of anticoagulation as risk indicator is consistent with previous studies, where the association between quality of anticoagulation and major bleeding was clearly demonstrated (Reynolds et al, 2004; Samsa et al, 2002).

Some limitations must be considered. Firstly, our study cohort consisted of patients treated more than 10 years ago. This could have resulted in "outdated" findings, and thereby limiting the generalisability of our findings. However, both the type of VKAs used and the strategy that was applied to achieve optimal anticoagulation in our study are still used in current practice, making our findings still applicable for current VKA therapy.

Unfortunately, at the time of data collection, information on important genetic factors related to the individual sensitivity to VKA (Gage \& Lesko, 2008; Hermida et al, 2002) was not available. Another limitation is the potential underreporting of bleeding complications in a 
study in which complications are collected during the course of regular treatment. However, we only included "new" patients and not those already on VKA at the time of the start of the study and we had access to detailed information regarding all bleeding complications during the one year of follow-up, including the minor bleeds. Furthermore, minor bleeds were assessed by the experienced staff of the anticoagulation clinic responsible for monitoring the VKA therapy and/or reported spontaneously by the patients themselves. Therefore, in our opinion underreporting was very limited, which is also indicated by the observed bleeding risk that is consistent with previous reports (Schulman et al, 2008; Palareti et al, 1996; van der Meer et al, 1993; Albers et al, 2005; Connolly et al, 2009; Linkins et al, 2003; Olsson, 2003; Palareti \& Cosmi, 2009; DiMarco et al, 2005; Go et al, 2003; Hylek et al, 2007). This is also supported by the sensitivity analysis excluding the haematoma, which are most prone for misclassification. In this respect, the associated risk after a haematoma was lower than after another type of minor bleed, although not significant. We can only speculate that this difference can be attributed to the "smaller" haematomas. However, as additional information on the size of haematomas was not available, this could not be evaluated.

A second issue regarding generalisability is the intensity of anticoagulation used in the Netherlands. To avoid, particularly, under-anticoagulation, the Dutch anticoagulation clinics use a therapeutic range which is 0.5 INR wider towards a higher intensity than the conventionally employed target ranges in other countries (e.g. INR 2.0-3.5 vs. INR 2.0-3.0). The target ranges that were used were 0.5 INR higher (e.g. INR 2.5-3.5 vs. INR 2.0-3.0). Despite the higher target ranges, the percentage of time within the target range as observed in our study (median ITTR 43\%) was comparable to those reported in previous studies (Ansell et al, 2008; Finn et al, 2003). The percentage of time with an INR above 5.0 was limited to only $3 \%$ of treatment time. Furthermore, with an absolute risk of major bleeding of 1.4 per 100 person-years, in the setting of a specialized anticoagulation clinic this strategy did not lead to excessive major bleeding. 
Therefore, in our opinion, the observed association of both poor anticoagulation and minor bleeding with major bleeding is still relevant for VKA therapy today.

In conclusion, minor bleeding is associated with subsequent major bleeding. The occurrence of a minor bleed should increase the awareness towards a potentially high-risk situation. In this, the achieved level of anticoagulation should also be considered, not just the INR at the time of the minor bleed, but especially the amount of over-anticoagulation during the preceding treatment period. In our study, we used the percentage of time above INR 5.0 during a 30-day period.

In line with this awareness, a renewed risk-benefit assessment should be performed. Whether a lower intensity of anticoagulation might be more suitable for these high-risk patients, without compromising the efficacy of VKA therapy to prevent thromboembolic complications is speculative. In this, also VKA as the anticoagulant drug of choice could be reconsidered. For some patients, no anticoagulant agent, aspirin, or - in the near future - an oral II or Xa inhibitor might be a more suitable option.

Authorship contributions:

Veeger, Piersma-Wichers and Hillege designed the research study. Piersma-Wichers contributed to data collection. Analysis was performed by Veeger. Veeger and Meijer drafted the manuscript. All authors participated in the interpretation and presentation of the study and approved the final version of the manuscript. 
References

Albers,G.W., Diener,H.C., Frison,L., Grind,M., Nevinson,M., Partridge,S., Halperin,J.L., Horrow,J., Olsson,S.B., Petersen,P., \& Vahanian,A. (2005) Ximelagatran vs warfarin for stroke prevention in patients with nonvalvular atrial fibrillation: a randomized trial. JAMA, 293, 690698.

Allison,P.D. (1995) Survival Analysis Using the SAS® System: A Practical Guide, pp. 1-292. Cary, NC: SAS Institute Inc..

Ansell,J., Hirsh,J., Hylek,E., Jacobson,A., Crowther,M., \& Palareti,G. (2008) Pharmacology and management of the vitamin K antagonists: American College of Chest Physicians EvidenceBased Clinical Practice Guidelines (8th Edition). Chest, 133, 160S-198S.

Azar,A.J., Cannegieter,S.C., Deckers,J.W., Briet,E., van Bergen,P.F., Jonker,J.J., \& Rosendaal,F.R. (1996) Optimal intensity of oral anticoagulant therapy after myocardial infarction. $J$ Am.Coll.Cardiol., 27, 1349-1355.

Beyth,R.J., Quinn,L.M., \& Landefeld,C.S. (1998) Prospective evaluation of an index for predicting the risk of major bleeding in outpatients treated with warfarin. Am.J.Med., 105, 91-99.

Connolly,S.J., Ezekowitz,M.D., Yusuf,S., Eikelboom,J., Oldgren,J., Parekh,A., Pogue,J., Reilly,P.A., Themeles,E., Varrone,J., Wang,S., Alings,M., Xavier,D., Zhu,J., Diaz,R., Lewis,B.S., Darius,H., Diener,H.C., Joyner,C.D., \& Wallentin,L. (2009) Dabigatran versus warfarin in patients with atrial fibrillation. N.Engl.J.Med., 361, 1139-1151.

DiMarco,J.P., Flaker,G., Waldo,A.L., Corley,S.D., Greene,H.L., Safford,R.E., Rosenfeld,L.E., Mitrani,G., \& Nemeth,M. (2005) Factors affecting bleeding risk during anticoagulant therapy in patients with atrial fibrillation: observations from the Atrial Fibrillation Follow-up Investigation of Rhythm Management (AFFIRM) study. Am. Heart J., 149, 650-656.

Fihn,S.D., Gadisseur,A.A., Pasterkamp,E., van der Meer,F.J., Breukink-Engbers,W.G., GevenBoere,L.M., van Meegen,E., Vries-Goldschmeding,H., Antheunissen-Anneveld,I., van't Hoff,A.R., Harderman,D., Smink,M., \& Rosendaal,F.R. (2003) Comparison of control and stability of oral anticoagulant therapy using acenocoumarol versus phenprocoumon. Thromb. Haemost., 90, 260-266.

Gage,B.F. \& Lesko,L.J. (2008) Pharmacogenetics of warfarin: regulatory, scientific, and clinical issues. J.Thromb.Thrombolysis., 25, 45-51.

Go,A.S., Hylek,E.M., Chang,Y., Phillips,K.A., Henault,L.E., Capra,A.M., Jensvold,N.G., Selby,J.V., \& Singer,D.E. (2003) Anticoagulation therapy for stroke prevention in atrial fibrillation: how well do randomized trials translate into clinical practice? JAMA, 290, 2685-2692.

Hermida,J., Zarza,J., Alberca,I., Montes,R., Lopez,M.L., Molina,E., \& Rocha,E. (2002) Differential effects of $2 \mathrm{C}^{*} 3$ and $2 \mathrm{C} 9^{*} 2$ variants of cytochrome P-450 CYP2C 9 on sensitivity to acenocoumarol. Blood, 99, 4237-4239.

Hylek,E.M., Evans-Molina,C., Shea,C., Henault,L.E., \& Regan,S. (2007) Major hemorrhage and tolerability of warfarin in the first year of therapy among elderly patients with atrial fibrillation. Circulation, 115, 2689-2696.

Kucher,N., Connolly,S., Beckman,J.A., Cheng,L.H., Tsilimingras,K.V., Fanikos,J., \& Goldhaber,S.Z. (2004) International normalized ratio increase before warfarin-associated hemorrhage - Brief and subtle. Archives of Internal Medicine, 164, 2176-2179. 
Kuijer,P.M., Hutten,B.A., Prins,M.H., \& Buller,H.R. (1999) Prediction of the risk of bleeding during anticoagulant treatment for venous thromboembolism. Arch.Intern.Med., 159, 457-460.

Linkins,L.A., Choi,P.T., \& Douketis,J.D. (2003) Clinical impact of bleeding in patients taking oral anticoagulant therapy for venous thromboembolism: a meta-analysis. Ann.Intern.Med., 139, 893-900.

McCormick,D., Gurwitz,J.H., Goldberg,R.J., Becker,R., Tate,J.P., Elwell,A., \& Radford,M.J. (2001) Prevalence and quality of warfarin use for patients with atrial fibrillation in the long-term care setting. Archives of Internal Medicine, 161, 2458-2463.

Olsson,S.B. (2003) Stroke prevention with the oral direct thrombin inhibitor ximelagatran compared with warfarin in patients with non-valvular atrial fibrillation (SPORTIF III): randomised controlled trial. Lancet, 362, 1691-1698.

Palareti,G. \& Cosmi,B. (2009) Bleeding with anticoagulation therapy - who is at risk, and how best to identify such patients. Thromb. Haemost., 102, 268-278.

Palareti,G., Leali,N., Coccheri,S., Poggi,M., Manotti,C., D'Angelo,A., Pengo,V., Erba,N., Moia,M., Ciavarella,N., Devoto,G., Berrettini,M., \& Musolesi,S. (1996) Bleeding complications of oral anticoagulant treatment: an inception-cohort, prospective collaborative study (ISCOAT). Italian Study on Complications of Oral Anticoagulant Therapy. Lancet, 348, 423-428.

Palareti,G., Legnani,C., Guazzaloca,G., Lelia,V., Cosmi,B., Lunghi,B., Marchetti,G., Poli,D., \& Pengo,V. (2005) Risks factors for highly unstable response to oral anticoagulation: a casecontrol study. British Journal of Haematology, 129, $72-78$.

Penning-van Beest,F.J.A., van Meegen,E., Rosendaal,F.R., \& Stricker,B.H.C. (2001) Characteristics of anticoagulant therapy and comorbidity related to overanticoagulation. Thrombosis and Haemostasis, 86, 569-574.

Reynolds,M.W., Fahrbach,K., Hauch,O., Wygant,G., Estok,R., Cella,C., \& Nalysnyk,L. (2004) Warfarin anticoagulation and outcomes in patients with atrial fibrillation: a systematic review and metaanalysis. Chest, 126, 1938-1945.

Rosendaal,F.R., Cannegieter,S.C., van der Meer,F.J., \& Briet,E. (1993) A method to determine the optimal intensity of oral anticoagulant therapy. Thromb. Haemost., 69, 236-239.

Samsa,G.P., Matchar,D.B., Phillips,D.L., \& McGrann,J. (2002) Which approach to anticoagulation management is best? Illustration of an interactive mathematical model to support informed decision making. J.Thromb. Thrombolysis, 14, 103-111.

Schulman,S. \& Kearon,C. (2005) Definition of major bleeding in clinical investigations of antihemostatic medicinal products in non-surgical patients. J.Thromb. Haemost., 3, 692-694.

Schulman,S., Beyth,R.J., Kearon,C., \& Levine,M.N. (2008) Hemorrhagic Complications of Anticoagulant and Thrombolytic Treatment: American College of Chest Physicians EvidenceBased Clinical Practice Guidelines (8th Edition). Chest, 133, 257S-298S.

Shireman,T.I., Mahnken,J.D., Howard,P.A., Kresowik,T.F., Hou,Q., \& Ellerbeck,E.F. (2006) Development of a contemporary bleeding risk model for elderly warfarin recipients. Chest, 130, 1390-1396.

The Stroke Prevention in Atrial Fibrillation Investigators (1996) Bleeding during antithrombotic therapy in patients with atrial fibrillation. Arch.Intern.Med., 156, 409-416.

van der Meer,F.J., Rosendaal,F.R., Vandenbroucke,J.P., \& Briet,E. (1993) Bleeding complications in oral anticoagulant therapy. An analysis of risk factors. Arch.Intern.Med., 153, 1557-1562. 
van der Meer,F.J.M., Briet,E., Vandenbroucke,J.P., Sramek,D.I., Versluijs,M.H.P.M., \& Rosendaal,F.R. (1997) The role of compliance as a cause of instability in oral anticoagulant therapy. British Journal of Haematology, 98, 893-900.

van Es,R.F., Jonker,J.J., Verheugt,F.W., Deckers,J.W., \& Grobbee,D.E. (2002) Aspirin and coumadin after acute coronary syndromes (the ASPECT-2 study): a randomised controlled trial. Lancet, $360,109-113$.

Veeger,N.J., Piersma-Wichers,M., Hillege,H.L., Crijns,H.J., \& van der Meer,J. (2006) Early detection of patients with a poor response to vitamin $\mathrm{K}$ antagonists: the clinical impact of individual time within target range in patients with heart disease. J.Thromb.Haemost., 4, 1625-1627.

Veeger,N.J., Piersma-Wichers,M., Tijssen,J.G., Hillege,H.L., \& van der Meer,J. (2005) Individual time within target range in patients treated with vitamin $\mathrm{K}$ antagonists: main determinant of quality of anticoagulation and predictor of clinical outcome. a retrospective study of 2300 consecutive patients with venous thromboembolism. British Journal of Haematology, 128, 513-519.

White,R.H., McKittrick,T., Takakuwa,J., Callahan,C., McDonell,M., \& Fihn,S. (1996) Management and prognosis of life-threatening bleeding during warfarin therapy. National Consortium of Anticoagulation Clinics. Arch.Intern.Med., 156, 1197-1201.

Wilkinson,G.R. (2005) Drug therapy - Drug metabolism and variability among patients in drug response. New England Journal of Medicine, 352, 2211-2221.

Wittkowsky,A.K. (2005) Factors associated with INR elevation and bleeding complications during warfarin therapy. Archives of Internal Medicine, 165, 703.

Wittkowsky,A.K. \& Devine,E.B. (2004) Frequency and causes of overanticoagulation and underanticoagulation in patients treated with warfarin. Pharmacotherapy, 24, 1311-1316. 
Legend

Table 1 Patient characteristics and anticoagulation data.

Table $2 \quad$ Type of major bleeds.

Table $3 \quad$ Major bleeding.

Figure 1 Hazard ratios of major bleeding, from survival analysis using a piecewise exponential model. Presented variables were included in final model. 


\section{Table 1 Patients' characteristics and anticoagulation data.}

\begin{tabular}{|c|c|}
\hline & $\begin{array}{c}\text { Total } \\
\mathrm{N}=5898\end{array}$ \\
\hline \multicolumn{2}{|l|}{ Patients' characteristics } \\
\hline Age, years ${ }^{\star}$ & $68(37-86)$ \\
\hline Male, \% & 52 \\
\hline Diabetes mellitus, \% & 9 \\
\hline Malignancy, \% & 4 \\
\hline \multicolumn{2}{|l|}{ Concomitant drugs, \% } \\
\hline low dose aspirin & 3 \\
\hline beta blockers & 5 \\
\hline calcium antagonists & 7 \\
\hline nitrates & 1 \\
\hline antiarrhythmic drugs & 8 \\
\hline diuretics & 10 \\
\hline lipid lowering drugs & 6 \\
\hline oral contraceptives/HRT ${ }^{\dagger}$ & 1 \\
\hline NSAIDs ${ }^{\#}$ & 7 \\
\hline \multicolumn{2}{|l|}{ Anticoagulation data ${ }^{*}$} \\
\hline Follow-up time (months) & $9.1(1.4-11.8)$ \\
\hline Number of INRs & $20(7-35)$ \\
\hline Time between INRs (days) & $13(3-28)$ \\
\hline $\mathrm{INR}^{\ddagger}$ & $3.0(1.6-5.7)$ \\
\hline Time with INR > $5.0(\%)$ & $3(0-23)$ \\
\hline $\operatorname{ITTR}(\%)^{\S}$ & $43(13-75)$ \\
\hline
\end{tabular}

* median (90\% central range); † hormone replacement therapy; \# Non-steroidal anti-inflammatory drugs; ¥ International Normalized Ratio; § Individual Time within Target Range; || INR stability is expressed as absolute daily INR change. 
Table 2 Type of minor bleeds.

\begin{tabular}{lc}
\hline Minor bleeds N (\%) & \\
\hline Total & $1501(100.0)$ \\
& \\
haematoma & $595(39.6)$ \\
nose bleed & $408(27.2)$ \\
conjuctiva bleed & $163(10.9)$ \\
haematuria & $143(9.5)$ \\
gastrointestinal bleed & $68(4.5)$ \\
haemoptoe & $32(2.1)$ \\
vaginal bleed & $28(1.9)$ \\
muscular bleed & $12(0.8)$ \\
other & $52(3.5)$ \\
\hline
\end{tabular}




\section{Table 3 Major bleeding.}

\begin{tabular}{lccc}
\hline TYPE OF EVENT * & \multicolumn{2}{c}{ Minor bleeding } & Total \\
& Yes & No & \\
& $\mathrm{n}=1015$ & $\mathrm{n}=4883$ & $\mathrm{n}=5898$ \\
Major bleeding $\mathrm{n}(\%)$ & $\mathbf{1 8 ( 1 . 8 )}$ & $\mathbf{3 8}(\mathbf{0 . 8 )}$ & $\mathbf{5 6}(\mathbf{0 . 9 )}$ \\
non-fatal gastrointestinal & 5 & 8 & 13 \\
fatal gastrointestinal & 1 & 1 & 2 \\
non-fatal intracranial & 1 & 4 & 5 \\
fatal intracranial & 2 & 5 & 7 \\
intra-ocular & 0 & 3 & 3 \\
other major bleeding\# & 9 & 17 & 26 \\
& & & \\
incidence rate $(95 \% \mathrm{Cl})$ per 100 & 2.3 & 1.2 & 1.4 \\
patient-years & $(1.4-3.7)$ & $(0.9-1.7)$ & $(1.1-1.9)$ \\
\hline
\end{tabular}

* The number of patients with at least one event is presented. In case of multiple bleeding, the first event was considered. \# Other bleeding adjudicated as major were haemoptoe (6; 2 in patients with a prior minor bleed and 4 in patients without a prior minor bleed), haematuria (4; 1-3), haematoma (2; 1-1), vaginal bleed (6; 2-4), nose bleed (2; $1-1)$, intra-articular bleed $(1 ; 1-0)$ and miscellaneous $(5 ; 1-4)$. 
Variable

Prior minor bleeding*

Over-anticoagulation ${ }^{*}$ *

Age 70 years or older

Malignancy

Diabetes mellitus

Use of duretics

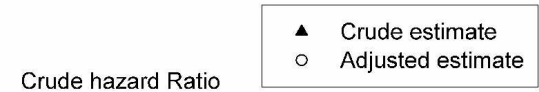
$(95 \% \mathrm{Cl})$

$3.2(1.3-8.0), P=0.014$

$2.3(1.3-4.0), P=0.005$

$1.7(1.0-3.0), P=0.054$

2.6 (1.1-6.6), $P=0.039$

$2.2(1.1-4.2), P=0.021$

2.7 (1.4-5.2), $P=0.002$

- Adjusted estimate

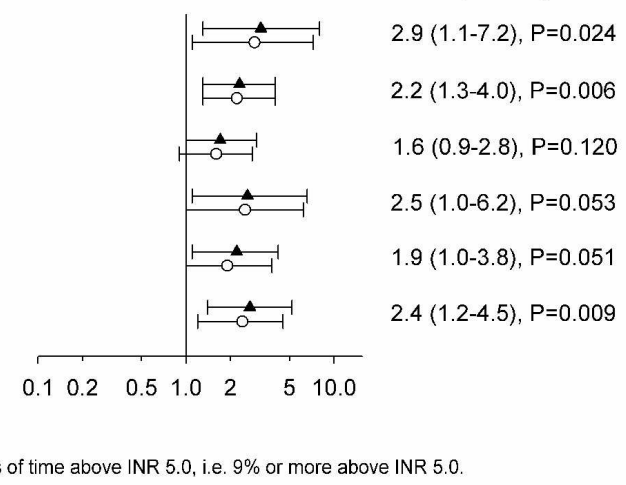

Figure 1 Hazard ratios of major bleeding, from survival analysis using a multivariable piecewise exponential model. Presented variables were included in the final model. $959 \times 479 \mathrm{~mm}(150 \times 150 \mathrm{DPI})$ 